\title{
ФИЛОСОФИЯ ГОРСКОГО БЫТИЯ В СЕВЕРОКАВКАЗСКИХ ЛИТЕРАТУРАХ И В НАУЧНОМ ТВОРЧЕСТВЕ Б.А. КАЛОЕВА
}

\author{
Р.Я. Фидарова \\ И.А. Кайтова
}

\begin{abstract}
Учитывая законы гносеологии, мы должны признать, что в исследовании философии горского бытия исторически участвуют два типа познания: художественно-образное познание и теоретическое, научное. При этом художественно-образное познание - более древнее, существующее еще со времен первобытности и отраженное в фольклорном типе художественного сознания, традици которого в познании философии горского бытия успешно переняли северокавказские литературы, зародившиеся и сбормировавшиеся в ХІХ-ХХ веках, как, скажем, осетинская, кабардинская, ингушская и др. Теоретическое, научное познание философии горского бытия успешно началось еще во второй половине ХІХ в. с помощью русских ученых В.Ф. Миллера и др. и осетинских историков-этнограбов, проделавших больщую работу по развитию начионального самосознания горских народов. Традиции данных, патриотически настроенных ученых, в ХХ веке продолжил большой отряд весьма образованных и не менее патриотически настроенных исследователей. Среди них особо выделяется Б.А. Калоев, предложивший свой собственный методологический подход к изучению горского бытия, свою концепиию философии горского бытия. Основная суть методологического подхода Калоева заключается в том, что в ней общественное бытие и общественное сознание гориев рассматриваются как взаимосвязанные и взаимообусловленные феномены, составляющие единое иелое, иелостную систему, определяюшую исторически всю философию горского бытия, ярко выражаютуюся в способе духовного освоения горскими народами объективного мира, мира национальной действительности.
\end{abstract}

Ключевые слова: горское бытие, горская семья, патронимия, адат, гостеприимство, побратимство, кровная месть, культ предков, посвящение коня.

Considering laws of gnoseology, we have to recognize that two types of knowledge historically are interwoven in a research of philosophy of mountaineers' life: artistic, figurative knowledge and theoretical, scientific. The artistic and figurative knowledge as a more ancient, existing since primitive times reflects type of art consciousness in folklore, traditions of which in the knowledge of philosophy of mountain life have successfully been adopted by the North Caucasian literatures starting in the XIX-XXth centuries as, say, Ossetian, Kabardian, Ingush, etc. Theoretical, scientific research of the philosophy of the mountaineers' life was successfully pioneered in the second half of the XIXth century by V. F. Miller and other Russian scientists and Ossetian historians-ethnographers, who have induced the development of national consciousness of the mountaineers. Traditions of these patriotically biased scientists was further developed by a big group of very educated and not less patriotically tuned researchers in the XX century. B.A. Kaloev, who has elaborated his own methodological approach to studying mountain life, the concept of philosophy of mountain life, is distinguished among them. The main essence of the methodological approach of Kaloev is that he considered social existence and public consciousness of the mountaineers as interconnected and interdependent phenomena making a whole, the complete system defining historically all philosophy of mountain life, which is brightly expressed in a way of spiritual development by the mountain people of the objective world, world of national reality.

Keywords: mountaine life, mountain family, patronymy, adat, hospitality, fraternization, blood feud, dedication of a horse to the dead ritual. 
Учитывая законы гносеологии, мы должны признать, что в исследовании философии горского бытия исторически участвуют два типа познания: художественно-образное и теоретическое, научное. При этом художественно-образное познание - более древнее, существующее еще со времен первобытности и отраженное в фольклорном типе художественного сознания, традиции которого в познании философии горского бытия успешно переняли северокавказские литературы, зародившиеся и сформировавшиеся в XIX-XX веках, как, скажем, осетинская, кабардинская, ингушская и др.

Теоретическое, научное познание философии горского бытия началось еще во второй половине XIX в. с помощью русских ученых В.Ф. Миллера и др. и осетинских историков-этнографов, проделавших большую работу по развитию национального самосознания горских народов.

Традиции этих, патриотически настроенных ученых, в XX в. продолжил большой отряд весьма образованных и не менее патриотически настроенных исследователей. Среди них особо выделяется Б.А. Калоев, предложивший свою концепцию философии горского бытия.

Основная суть методологического подхода Калоева заключается в том, что в ней общественное бытие и общественное сознание горцев рассматриваются как взаимосвязанные и взаимообусловленные феномены, составляющие единое целое, целостную систему, определяющую исторически всю философию горского бытия, ярко выражающуюся в способе духовного освоения мира горскими народами.

Обратимся вкратце к теоретическому «инструментарию», который активно использует ученый в своем научном творчестве при формировании концепции философии горского бытия. Так, Калоев использует метод восхождения от абстрактного к конкретному, принцип объективности, принцип развития, позволяющие ему учитывать объективный и диалектический характер общественного бытия и общественного сознания горцев. Принцип преемственности в концепции ученого дает ему возможность выявить преемственные связи далекого прошлого и настоящего. Принцип противоречия способствует лучшему познанию сложного характера горского бытия, а принцип историзма - особенности его эволюции в ходе исторического развития. Структурный подход с его особым взглядом на исторический процесс помогает Калоеву выявить на протяжении довольно большого отреза времени более или менее стабильные, устойчивые компоненты бытия и сознания горцев. Сравнительно-исторический метод, с помощью которого, путем сравнения, выявляется общее и особенное в бытии и сознании горцев, помогает ученому познать важнейшие тенденции горского экзистенциального бытия. Анализируя это бытие с точки зрения детерминизма, Калоев устанавливает его зависимость от природных, социальных и иных факторов.

Ученый использует и цивилизованный подход, смысл и значение которого - в выявлении универсальных черт на разных этапах развития горского бытия. Системный подход помог ему исследовать горское бытие как систему, что в совокупности дало возможность построить целостную стройную концепцию философии бытия. И конечно, Калоев умело привлекал социологические, этнологические, этнографические, социально-психологические и др. методы исследования, что помогло ему глубоко, всесторонне, концептуально осмыслить горское бытие.

В целом у Калоева сформировался тип научного мышления, способный ставить и решать философско-концептуаль- 
ные, «метафизические» проблемы горского бытия, анализировать объективное «состояние мира».

Но, если мы обратимся к эстетическому опыту северокавказских литератур, на современном этапе ярко представляющих такой тип познания, как художественно-образный, то заметим, что они также концептуально и всесторонне, с учетом логики причинно-следственных связей, отражают философию горского бытия, дают глубинный, сущностный анализ «метафизических» проблем, анализ объективного «состояния мира», который еще Гегель выделял как важнейшую жанровую черту романа $[1,203]$. Решив в данной статье кратко сопоставить два типа познания философии горского бытия, а именно: художественно-образный, представленный эстетическим опытом северокавказских литератур, и теоретический, выраженный в научном творчестве Калоева, обратимся к некоторым примерам.

1. Калоев, анализируя своеобразие общественных и семейных отношений, исторически сложившихся у горцев, отмечает такие формы, как патронимия, фамилия первого порядка (т.е. фамилия простая) и фамилия второго порядка. Как выясняет ученый, например, у осетин патронимия имеет несколько названий: иy фылы фыыртта (дети от одного отца), иу артай байуарга (от одного очага разделившиеся), дыггаг хадзар (второй дом). По мысли ученого, такая общественная форма - результат сегментации или распада семейной общины. Она объединяет несколько больших и малых семей, которые затем в дальнейшем распадались еще на новые, более мелкие семьи. Каждая патронимия носила имя своего основателя - главы дома, давшего начало этой группе. Жили они компактно: отдельными селами или кварталами.

Хозяйственное единство патронимии проявлялось в совместной обработке земли. У них была общая пахотная земля, сенокосные угодья, мельница, сельхозорудия, транспортные средства, хозяйственные помещения. Экономическое единство проявлялось во взаимопомощи в период сельскохозяйственных работ, при строительстве дома, при устройстве свадеб, похорон и т.д. Управлял патронимией совет, куда входили главы семейств. При этом старший имел решающий голос. Как подчеркивает Калоев, «глава осетинской семейной общины назывался хадзары хицау (глава дома)» $[2,36]$.

Особо отмечает ученый положение женщины в горском обществе.

«В осетинской семейной общине обязанности среди женщин были строго разграничены. Приготовление пищи считалось делом старшей невесты. В некоторых многочисленных семьях хлеб пекли по очереди обычно две женщины. В обязанности старших невесток входило также приготовление молочных продуктов, в частности, сыра, занимавшего значительное место в пищевом рационе осетин. Носить воду, растапливать печь, доить коров, а также убирать жилье и скотные помещения и даже двор - все это входило в обязанности младших невесток. Длительное сохранение натурального хозяйства у осетин... вынуждало их делать почти всю одежду в домашних условиях. Много времени и труда каждая женщина тратила на изготовление домотканого сукна. Обработку шерсти и изготовление из нее пряжи женщины производили совместно под руководством старших женщин, обладавших большим опытом и знанием дела. Кройка черкесок, бешметов, шуб и их шитье также поручались опытным мастерицам, пользовавшимся в семье и в обществе особым уважением» $[2,308]$.

Общественная сущность патронимии, по мнению ученого, проявлялась также и в обязательном участии всех ее членов в обеспечении безопасности. 
Так, у каждой патронимии в горах была своя башня, в которой укрывались во время вражеского нападения.

Идеологическое единство проявлялось в наличии единой кунацкой, где совместно принимали гостей, а также в проведении совместных праздников в честь родовых и общих покровителей (дзуаров) и т.д.

Как отмечает Калоев, «было несколько причин сохранения больших семей у осетин столь длительное время, независимо от их места жительства - в горах или на равнине. Во-первых, это малоземелье, не позволявшее делить общесемейные земельные участки - главный источник существования родственного коллектива. Во-вторых, использование традиционных орудий труда, особенно в горной полосе, требовало большого количества рабочих рук. Следуя известной поговорке "Иунаг магур у" (одинокому живется бедно), осетины старались по возможности сохранить большие семьи, чтобы иметь в хозяйстве хоть какой-то достаток» [2,303].

Итак, развитие горской семьи «...характеризуется рядом исторических этапов, начиная от первобытно-общинных ее форм до появления индивидуальных семейных ячеек. У осетин долгое время сохранились большие семьи или семейные общины, отличавшиеся весьма глубоким архаизмом» [2,301]. В 80-90-х годах XIX в., в период развития «капитализма... проникновение товарно-денежных отношений в осетинскую деревню явилось главной причиной, способствовавшей распаду семейной общины» $[2$, 309].

В это время происходили важные события в общественных и семейных отношениях. «В семейных общинах, где была избыточная мужская рабочая сила, большое значение, особенно в конце XIX в. приобрели отхожие промыслы». Калоев отмечал, что горцы массами покидали родину и отправлялись на заработки в далекие края [2,303].

Эти особенности в диалектике и динамике общественных и семейных отношений, существенным образом отразившиеся как на философии горского бытия в целом, так и на исторической судьбе горской семьи, проявились и в художественно-эстетическом сознании, в северокавказских литературах. Возьмем романы осетинского писателя Г. Черчесова «Заповедь» и «Испытание», в которых весьма убедительно раскрыто, как исторические обстоятельства (проникновение товарно-денежных отношений, развитие капитализма на Кавказе) воздействуют на семейные и общественные отношения, и как, в какой степени, казалось бы, маленький национальный мирок горцев «погружен» в большой, общечеловеческий мир. Рассмотрим, как это происходит в романе «Заповедь». Прежде всего, писатель вводит нас в весьма замкнутый мир жителей горного села Хохкау. Он представляет нам четыре фамилии, которые испокон веков живут в Хохкау, и каждая из которых имеет свой социальный статус. Соответственно, между ними устанавливаются определенные субординационные отношения. Но со временем происходит любопытный процесс: как, казалось бы, наглухо закрытый для внешних влияний, непроницаемый национальный мир под влиянием грандиозных социальных потрясений вдруг «взрывается». Разрываются неразрывные, казалось бы, связи: социальные обстоятельства оказываются сильнее вековых традиций. Многие поколения жили в Хохкау, никто не помнит, кто основал село. Здесь рождались, женились, рожали детей и, завершив свой жизненный путь, умирали люди. Мало что менялось со временем в их образе жизни. Собравшись на праздник, старейшина говорил горделиво, что среди его рода нет и не было лентяев, пьяниц, трусов, ни о ком 
из них не сложили позорную песню, ведь испокон веков воспитывали в детях трудолюбие, отвагу, скромность и почитание чести предков [3, 102].

У каждого со своим родом тоже складываются определенные отношения, регулируемые неписаным сводом законом - адатами. Скажем, если ты родился в сильной фамилии, считай себя счастливцем: никто не посмеет тебя обидеть, задеть грубым словом, оскорблять даже взглядом, - за все, обидчик понимает, он получит сполна. За кровь твою ответят кровью. Но и ты с самого рождения как бы берешь на себя «юридические» обязательства: ты не смеешь позорить род, т.е. идти против его порядков и интересов. И если твои собственные интересы расходятся с его интересами, ты пренебрегаешь своими, так сказать, «наступаешь на горло собственной песне». Род может вынести самый суровый приговор любому своему члену: сбросить со скалы, убить, прогнать и т.д.

Навсегда опозоренным считается человек, бежавший с поля боя, или не проявивший гостеприимство, или напившийся публично. Такова суровая народная мораль, духовная атмосфера замкнутого мира четырех фамилий в селе Хохкау, куда приходят отец и его 8 сыновей - род Гагаевых. Они-то в полной мере испытывают на себе силу и власть многих традиций местного общества, когда ныхас, этот всесильный орган народного самоуправления, состоящий из самых уважаемых и авторитетных стариков Хохкау, может их принять, а может и выгнать, лишив прав поселения.

Такова специфика общественных и семейных отношений в горском обществе, творчески осмысленная в научном творчестве и эстетическом опыте северокавказского романа.

Как исследует Калоев, очаг является символом единства семьи. При этом он связывает религиозное почитание очага и надочажной цепи с культом предков. Как подчеркнул ученый, культ предков особо почитаем у горцев [2, 293]

Столь ревностное почитание очага как священного символа единства семьи хорошо продемонстрировано в романе ингушского писателя И. Базоркина «Из тьмы веков». Главный герой романа Калой, которому после гибели его родителей, родственники предлагают свой кров и дом, т.е. практически предлагают отречься от своего рода и стать «пришедшим братом», принимает твердое решение остаться с малолетним братом Орци в родовой башне. «Вам всем спасибо, сказал он людям. - Я знаю, что ваши слова от сердца. Но в этой башне никогда не угасал очаг отцов. Около этого очага живут их души. В этой башне сегодня горе: завтра может быть радость. Так бывает. Наш род не прекратился. Нас с братом опять двое...» [4,289] Так понял и выразил мудрую диалектику жизни герой, сознание которого, «питающееся» наивной верой в то, что души предков объединяет родной очаг и соединяет крепкими узами с прежним местом жительства, пытается понять истинный смысл жизни.

Анализируя общественные отношения горцев, Калоев выделяет обычай кровной мести как пережиток патриархального общества, сохранявшийся вплоть до конца XIX в. [2,294]

Кровная месть как явление социально-исторического значения, как негативный фактор, ведущий к уничтожению самого прекрасного и ценного - самой человеческой жизни, иногда к бессмысленному истреблению целого рода, осмысляется и художественным сознанием горцев, северокавказскими литературами. Так, герой романа Г. Черчесова «Испытание» старик Дзамбулат, не одобряя в душе кровную месть как социальное явление, утверждает в общем-то народную точку зрения на это бессмысленное убийство. Он вспоминает: «когда наши 
две фамилии истребили друг друга настолько, что осталось в каждой по 10 дворов, Дудоевы с помощью одной из наших женщин выкрали у нас, Гагаевых, грудного ребенка и усыновили его. Так был положен конец кровной мести. Кто эта женщина - неизвестно, но она была поистине мудра: проливать кровь всегда плохо, и кто кровопролитие остановит, тот достоин всенародного уважения» $[5,231]$. Такова суть народного гуманизма, отраженная в жанре романа. Гуманизм народа черпает свои истоки в недрах философии его духа, в идее бессмертия народа, непреодолимости жизненного процесса на земле. Всепобеждающая сила народного духа, его вековая неиссякаемая мудрость выразились в образе славного, симпатичного и в то же время не лишенного юмористических красок деда Дзамбулата.

Среди обычаев традиционного общества Калоев особо выделяет гостеприимство: «Нарушение закона гостеприимства считалось большим позором не только для самого виновника, его родственников, но и для всех его ближайших однофамильцев. И, наоборот, горец, отличившийся гостеприимством, был известен далеко за пределами своего села и пользовался особым уважением. Имена таких людей нередко упоминаются в героических песнях. Наличие во дворе каждого хозяина коновязи служит также свидетельством строгого соблюдения закона гостеприимства у осетин в прошлом. Появление гостя в доме встречалось словами: «Уазаг - Хуыцауы уазаг» - «Гость божий гость», даже если он был нежелательным. Тем не менее, какой бы гость ни явился в дом, по обычаю гостеприимства он встречал радушный прием» $[2,294]$.

Прием гостей сопровождался сложными церемониями.

«Сколько бы гость ни оставался и какая бы рабочая пора ни была, - пишет Калоев, - старший дома или патронимии не покидал его ни на один час. Гостей укла- дывали спать в гостиной, соблюдая при этом определенный порядок: пока старший гость готовился ко сну, все остальные гости и хозяева стояли около него. Младший гость или один из сыновей хозяина снимал ему обувь и мыл ноги. Обувь снимали и другим гостям, но ноги они мыли себе сами. Характерно, что обувь сначала снимали с левой ноги...» $[2,296]$

Не менее церемониально и прощание с гостем. «При прощании гостя провожали одни мужчины, в присутствии женщины он не имел права сесть на коня или на арбу. Держа левой рукой бурку, башлык и плеть, гости подходили к своим коням. Здесь они, переложив вещи в правую руку и повернув коней головой к дому, садились по старшинству. Сидя на лошади, не полагалось прощаться за руку. Не полагалось также ударять коня, находясь еще около дома, так как хозяин мог подумать, что гость чем-то остался недоволен. В старину хозяин провожал гостя за село, а иногда до следующего гостеприимного пристанища» $[2,297]$.

Церемониально было и поведение гостя: «Подъезжая к коновязи у дома, писал Калоев, - гость останавливался и, сидя на коне, ждал до тех пор, пока хозяин не выходил ему навстречу. Затем он слезал с коня, брал в левую руку плеть, башлык, бурку и, поздоровавшись со своим будущим хозяином, отдавал эти вещи мальчику. Направляясь в дом за хозяином, гость вступал во двор правой ногой, а покидая гостеприимный дом, выходил левой» $[2,295]$.

А между тем его торжественного ожидали. «Этикет требовал от гостя проявления умеренности, сдержанности в еде, как бы он ни был голоден» $[2,296]$. При этом и хозяин должен был вести себя корректно. «Напоить гостя допьяна считалось большим позором для хозяина. Как только переставал есть старший гость, прекращали есть и все остальные гости» $[2,296]$. 
Во всех жанрах северокавказских литератур, в том числе в трилогии А. Кешокова «Вершины не спят», романе И. Базоркина «Из тьмы веков», романах Г. Черчесова «Заповедь» и «Испытание», да и во многих других, обычаи гостеприимства, куначества, как особой формы дружбы у горских народов, как непременный принцип горского бытия, отражаются ярко, образно передают неповторимый «аромат», особенное обаяние горского бытия.

Калоев особо выделяет такой аспект горского бытия, как побратимство (ардхорд). «У осетин, - пишет он, - ритуал побратимства таков: братающиеся наполняли бокал аракой или пивом и бросали туда монету, и каждый трижды пил из бокала, клянясь в верности... Приведенный обряд является одним из убедительных свидетельств значения иранского элемента в этногенезе осетин и степени преемственности культуры осетин от скифо-сарматов и алан» [2.299].

Интересно описан данный обряд и в романе «Из тьмы веков». У горцев самой верной клятвой является клятва огнем, хлебом и землей. Так, Калой со своими друзьями решил скрепить побратимство, подошел к очагу и взялся за цепь. И тотчас же над его рукой на цепь «легло еще пять рук, - и он сказал: «клянусь» $[4,219]$. И все повторили за ним эту клятву. Суровая действительность заставляла горцев бережно относиться к таким понятиям, как очаг, хлеб, земля, огонь: очаг символизировал жизнь, а хлеб и земля, которых в горах всегда не хватало, нужны были, чтобы жить.

В структуре художественного мира романа эта традиция играет также свою роль, участвуя в процессе формирования национальной сути горского бытия. «Послушай, это хлеб божий? - в особом эмоциональном состоянии, волнуясь и беспокоясь за будущее, говорит мать Зору. - Так вот, пусть каждый кусок его станет мне греховным, если я не убью себя, коль не сдержу слова!» $[4,223]$.

Весьма важным компонентом горского бытия Калоев считал ныхас как общественный совет. «Ныхас, - писал он, - имел большое значение в общественной жизни осетин вплоть до недавнего времени. На ныхасе решались вопросы, касающиеся всего общества или отдельных его членов. В круг функций ныхаса входило право распределения общественных земель, вынесение решения о времени начала полевых работ, о ремонте или строительстве дорог, мостов, о найме общественного пастуха и т.д.» $[2,299]$.

И далее он отмечал: «Ныхас, представлявший собой первоначально совет родовых старейшин, был важнейшим органом управления у предков осетин-алан. Свидетельством этого могут служить данные фольклора и некоторые памятники материальной культуры» $[2,299]$.

В романе Г. Черчесова «Заповедь» ныхас описан как общественный совет, как важнейший компонент структуры горского бытия. На ныхас, который должен был обсудить просьбу Гагаевых о разрешении поселиться в данном ауле, Дзамбулат деликатно запоздал: хотел дать возможность старикам обсудить без него его вопрос. Тактичный Гагаев оказался и провидцем: как он и предполагал, старцы на ныхасе попытались вытянуть у него как можно больше обещаний, выставить серьезнейшие условия, которые потом придется выполнять не только самому Дзамболату, но и всем его потомкам: здесь все передается из поколения в поколение. Кратко изложив просьбу, старший Гагаев сказал, что дом построит за оврагом из обычного камня, а чтобы, участок не заливало, намерен строить дамбу на повороте реки. Всем идея понравилась, но беспокоило одно: где пришелец возьмет землю, ее в горах всегда не хватает. На этот вопрос тоже был готов ответ: Гагаев с восьмью сыновьями засыпит овраг 
и будет разводить картофель и кукурузу. За право вхождения в общество хохкауцев Дзамболат с сыновьями обязан был охранять аул от абреков со стороны оврага. После долгих раздумий ныхас решил принять Гагаевых. «С сегодняшнего дня мы считаем тебя своим, - сказал Асланбек. - Аул будет тебя защищать как своего, но и ты должен подчиняться всем нашим решениям и законам. В чьей арбе сидишь, - говорят наши мудрецы, - того песню и пой» $[3,83]$.

Так, новички Гагаевы включаются в орбиту движения хохкауского братства и жизнь каждого из них подчиняется уже логике этого движения, законам данного братства... Но идет время, и законы социального движения оказываются сильнее законов жизни горцев: интенсивно протекают процессы социальной дифференциации, социального расслоения хохкауцев. Тотиковы все больше обогащаются, другие фамилии все больше беднеют. А что касается пришлых Гагаевых, то они, как самые бесправные и безземельные, вообще нищенствуют и жизнь их безжалостно разбрасывает по всему миру. В поисках лучшей доли Касполат и Пигу отправляются в Сибирь. Не сказав ничего, ночью исчезает Газак. Собрался в дорогу Тембол: он решил посетить Мекку и стать истинным мусульманином. Ну а Мурат отправился в Америку в надежде заработать деньги на калым... Из большой семьи дома с отцом остались только Умар и Урузмаг...

Главное достижение северокавказского романного мышления заключается в том, что оно художественно убедительно отразило процесс становления горских наций, показало пути перехода северокавказцев от одного стиля народного бытия с его пережитками патриархального общества к другому - буржуазному. Так, северокавказские литературы в сложных поисках художественно-эстетических идеалов реализовали одну из своих важ- нейших функций - отразили философию горского бытия, проявив тем самым свою профессиональную зрелость.

Не оставил без внимания Калоев и таков ритуал, как посвящение коня умершему. Он отмечал, что большой интерес у горцев представляют такие составляющие данного обычая, как сам факт посвящения, во-первых; личность старика - посвятителя (бахфалдисаг), во-вторых; и, в-третьих, речь посвятителя, в которой говорится «о предстоящем путешествии покойника в загробный мир на коне, а также о хороших земных делах умершего» $[2,330]$.

По существу в данной речи формулируется целый нравственно-этический кодекс праведной жизни горца. В самом обряде отражаются особенности мифоэпического, мифологического мышления. И это весьма умело осмыслено в художественном мире северокавказского романа, в которой частная национальная модель общечеловеческого бытия целостно охватывает само это бытие на всех уровнях. И в ней, в этой частной модели, право на существование имеют, почти наравне с человеческой личностью, и предметы, явления. В этом суть эпического принципа. В то же время по логике и диалектике единичного и всеобщего, абстрактного и конкретного герои в процессе обобщения приобретают свою индивидуальную неповторимость. Герой нартов всю свою жизнь воюет, почти все свое субъективное время, т.е. время своего индивидуального эпического бытия, проводит на коне, с оружием в руках. Поэтому в мифоэпическом сознании герой органически связан со своим конем, оружием и одеждой и составляет с ними неразрывное целое. И если герой по своим индивидуальным, психологическим качествам - явление исключительное, то печать его исключительности лежит и на каждом из звеньев единого целого: и конь его хорош, и оружие его необычно. 
По этому пути художественных исканий идет кабардинский писатель А. Кешоков. Князь Жираслан, герой трилогии «Вершины не спят», один из лучших наездников Кабарды, известный на всю Кабарду под прозвищем «князь-конокрад», сорокалетний красавец, отлично разбирается в лошадях, любит их, ценит. Психологическая сложность, противоречивость характера Жираслана подчеркивается его отношением к лошади. Приглашенный на сход аульчан, посвященный обсуждению проблемы конокрадства, ставшего чуть ли не социальным бедствием в округе, спокойно, не смущаясь, подъехал к собравшимся. Жираслан «спрыгнул с кошачьей легкостью, повел плечами, оправляя дорогую черкеску, звучно потрепал по шее коня, сказал: «Домой, Шагди!» Помахав головой и поводя глазом на хозяина, как бы вникая в приказание, показав сильные ляжки, поднял голову, словно всматри- ваясь, куда ему нужно идти, конь рысью пошел обратно по дороге» $[6,57]$. А вот еще одно описание, в котором герой и конь действуют как одно целое: «...волна сразу хлестнула по лошади. Умный конь, чувствуя себя вожаком, ступал осторожно, обходя подводные валуны, принюхиваясь к воде. Астемир подался всем телом вперед, опустил поводья, но зажал круп коня: лошадь чутка как ни одно животное, она ни на мгновение не должна чувствовать неуверенность седока, и всадник каждую минуту должен быть готовым поддержать коня своей волей» $[6,109]$.

Итак, в двух типах познания: художественно-образного, выраженного эстетическим опытом северокавказских литератур, и теоретического, представленного в научном творчестве профессора Б.А. Калоева, сформирована своеобразная, целостная и цельная концепция философии горского бытия.

1. Гегель Г.В. Эстетика. В 4-х т. М., 1969. Т. 2.

2. Калоев Б.А. Осетины. Историко-этнографические исследования. 3-е изд., испр. и перераб. М., 2004.

3. Черчесов Г. Заповедь. Роман. Орджоникидзе, 1980.

4. Базоркин И. Из тьмы веков. Роман. Грозный, 1982.

5. Черчесов Г. Испытание. Роман. Орджоникидзе, 1984.

6. Кешоков А. Вершины не спят. Трилогия / Перевод с кабардинского. Собр. соч. в 4-т. М., 1981. T. 1. 